\title{
Degradability of cross-linked polyurethanes/chitosan composites $^{*}$
}

\author{
Joanna Brzeska ${ }^{1), * *)}$, Magda Morawska ${ }^{1)}$, Aleksandra Heimowska ${ }^{1)}$, Wanda Sikorska ${ }^{2)}$, \\ Agnieszka Tercjak ${ }^{3)}$, Marek Kowalczuk ${ }^{2), 4)}$, Maria Rutkowska ${ }^{1)}$
}

DOI: dx.doi.org/10.14314/polimery.2017.567

\begin{abstract}
Polyurethanes with synthetic poly([R,S]-3-hydroxybutyrate) in the soft segment and with polycaprolactone triol as cross-linker were blended with chitosan and degraded in hydrolytic and oxidative solutions. Progress of the degradation of the samples was evaluated by changes in their weight, surface topography and thermal properties. Increasing the poly([R,S]-3-hydroxybutyrate) content in soft segment as well as blending with chitosan resulted in an increase in degradability of cross-linked polyurethanes in both solutions.
\end{abstract}

Keywords: cross-linked polyurethanes, chitosan, composites, polyurethane degradability.

\section{Podatność na degradację kompozytów usieciowanych poliuretanów $\mathrm{z}$ chitozanem}

Streszczenie: Poliuretany zawierające syntetyczny poli([R,S]-3-hydroksymaślan) w segmencie giętkim oraz polikaprolaktonotriol jako związek sieciujący zmieszano z chitozanem i poddano degradacji w roztworach hydrolitycznym i utleniającym. Postęp rozkładu kompozytów oceniano na podstawie zmiany masy, powierzchni i właściwości termicznych próbek. Zarówno zwiększenie zawartości poli([R,S]-3-hydroksymaślanu) w segmencie giętkim poliuretanów, jak i zmieszanie ich z chitozanem spowodowało wzrost podatności usieciowanych poliuretanów na degradację w obu rodzajach roztworów.

Słowa kluczowe: usieciowane poliuretany, chitozan, kompozyty, podatność poliuretanów na degradację.

Cross-linked polyurethanes (PUR) are mainly obtained in the reaction of isocyanates with polyols and low-molecular compounds, of which at least one type of reagent is multifunctional [1-3]. They can be also synthesized via reaction with using unsaturated compounds $[4,5]$. Cross-linked polyurethanes are not dissolved in the solvent but swelled. With an increase in the degree of

\footnotetext{
1) Gdynia Maritime University, Department of Chemistry and Commodity Industrial Science, Morska 83, 81-225 Gdynia, Poland.

2) Centre of Polymer and Carbon Materials Polish Academy of Sciences, Sklodowskiej-Curie 34, 41-819 Zabrze, Poland.

3) University of the Basque Country (UPV/EHU), Department of Chemical and Environmental Engineering, Group “Materials+Technologies" (GMT), Plaza Europa 1, 20018 Donostia-San Sebastián, Spain.

4) University of Wolverhampton, Faculty of Science and Engineering, School of Biology, Chemistry and Forensic Science, Wolverhampton WV1 1SB, UK.

*) This material was presented at $9^{\text {th }}$ International Conference MoDeSt 2016, 4-8 September 2016, Cracow, Poland.

**) Author for correspondence; e-mail: j.brzeska@wpit.am.gdynia.pl
}

cross-linking their elasticity decreases but stiffness increases. They are mainly used as coatings, membrane and shape memory materials [6].

Cross-linked polyurethanes are generally less susceptible to degradation than linear polyurethanes. The presence of cross-linkages between chains of polyurethane significantly hinders the migration of water with enzymes, free radicals, and other degradative molecules into the polymer network [6].

But, in some cases, the presence of a triol cross-linker in polyurethane structure leads to a polymer with no phase separation. Disordering of the polymer network and reduced mobility of the chains (as a result of chemical cross-linking) allow the ester/ether groups to be exposed to water. In this case cross-linked polyurethanes can be susceptible to degradation [7].

The process of degradation of cross-linked polyurethanes can be accelerated by introducing the groups susceptible to degradation (such as ester groups) into their structure or by blending with degradable polymers. Natural polymers or their synthetic analogues (such as polyhydroxybutyrate, polycaprolactone, and chitosan) can be used as part of polyurethane network or as composite fillers. 
Chitosan is a very promising material because of its properties and high availability of the raw material (chitin) in nature. Chitosan is obtained via deacetylation of chitin [8]. Because of non-toxicity, antibacterial and antifungal activity, biocompatibility, biodegradability, adhesiveness, mucoadhesion, high charge density and ability to form the chelate compounds as well as gels chitosan can be used in medicine $[9,10]$, textile [11] and paper preparation [12], in environmental protection (as absorber of contaminants from water $[13,14])$, in pharmaceutical, cosmetic, food and agriculture industry [15].

In medicine, it has been used (and still investigated) for reduction of cholesterol, as wound dressing, for bone and cartilage reconstruction, drug and enzymes delivery, and blood cells separation [16].

Chitosan can be introduced into the polyurethane structure [17], grafted onto polyurethane chains [18] or immobilized onto the polyurethane surface through electrostatic reaction [19] or covalent bonds [20]. Also, it can be used for preparation of polyurethane composites [21, 22].

The aim of the work was the estimation of degradability of cross-linked polyurethanes (based on polycaprolactone triol and polyhydroxybutyrate) and their composites with chitosan in hydrolytic and oxidative solutions.

\section{EXPERIMENTAL PART}

\section{Materials}

- Polycaprolactone triol (PCL-triol) $\left(M_{n}=900\right.$, Aldrich); - poly $\left([R, S]-3\right.$-hydroxybutyrate) (PHB, $\left.M_{n}=1700\right)$, obtained by anionic ring opening polymerization of $(R, S)-\beta$-butyrolactone initiated by 3-hydroxybutyric acid sodium salt/18-crown-6 complex at room temperature and terminated with 2-bromoethanol [23];

- aliphatic 4,4'-methylene dicyclohexyl diisocyanate ( $\mathrm{H}_{12} \mathrm{MDI}$, Aldrich);

- 1,4-butanediol (1,4-BD, Aldrich);

- tin(II) octoate (OSn, Aesar) as catalyst;

- N,N-dimethylformamide (DMF, Chempur);

- chitosan (Ch, MIR [24]).

\section{Samples preparation}

Polyurethanes were synthesized in two-step polyaddition reaction. The soft segments of polyurethanes were built of polycaprolactone triol and synthetic poly $([R, S]-$ -3-hydroxybutyrate) [23]. The hard segments were synthesized from aliphatic 4,4'-methylene dicyclohexyl diisocyanate and 1,4-butanediol. Before the synthesis, polyols (PHB and PCL-triol) were dried by heating at $60{ }^{\circ} \mathrm{C}$ for 3 hours under reduced pressure $(1.4 \mathrm{hPa})$. Prepolymer was synthesized from polyols and $\mathrm{H}_{12} \mathrm{MDI}$ (and with $0.02 \mathrm{wt} \%$ of OSn) for $3 \mathrm{~h}$ at $70-75{ }^{\circ} \mathrm{C}$, under reduced pressure. Next, the prepolymer was dissolved in $N, N$-dimethylformamide (DMF) and prolonged using
1,4-BD as chain extender for 2 hours. Foils were formed on Teflon plates by heating (after solvent evaporation) at $105{ }^{\circ} \mathrm{C}$ in a vacuum drier.

Chitosan was previously triturated to small particles (size of 50-350 $\mu \mathrm{m}$ ) in a mortar, and introduced into PUR solution in DMF after prepolymer extension and before foil formation. The rate of deacetylation of the chitosan used was $97 \%$, its molecular weight $M_{n}=171000$.

The thermal properties of native chitosan - first melting temperature: $81.3^{\circ} \mathrm{C}$, onset point $48.5^{\circ} \mathrm{C}$, melting enthalpy $186.5 \mathrm{~J} / \mathrm{g}$, and second melting temperature: $142.7^{\circ} \mathrm{C}$, onset point $123.3^{\circ} \mathrm{C}$, melting enthalpy $40.1 \mathrm{~J} / \mathrm{g}$ were determined by differential scanning calorimetry (DSC).

\section{Methods of testing}

Thermal properties of chitosan, polyurethanes and their composites were determined by differential scanning calorimetry (DSC). DSC measurements were made using Setaram Thermal Analyser with indium and lead used for calibration. The specimens (with mass about $20 \mathrm{mg}$ ) were sealed in aluminum pans and scanned from $20{ }^{\circ} \mathrm{C}$ to $200{ }^{\circ} \mathrm{C}$ with heating rate of $10^{\circ} \mathrm{C} / \mathrm{min}\left(1^{\text {st }} \mathrm{scan}\right)$, next they were cooled to room temperature and again heated to $200{ }^{\circ} \mathrm{C}$ with heating rate of $10{ }^{\circ} \mathrm{C} / \mathrm{min}$ ( $\left(2^{\text {nd }} \mathrm{scan}\right)$. All experiments were carried out in a flow of dry $\mathrm{N}_{2}$.

Morphological analysis of polymer surface was conducted by atomic force microscopy (AFM) and using metallographic microscope (MM). AFM images were obtained when operating in tapping mode (TM-AFM) with a scanning probe microscope (Dimension ICON Bruker) equipped with an integrated silicon tip/cantilever with a driving frequency around $300 \mathrm{kHz}$. Different areas of each investigated sample were analyzed to ensure the final morphology of investigated materials. Taken into account the similarity between height and phase AFM images, only AFM phase images are shown here. The average roughness $\left(R_{a}\right)$ was calculated using height AFM images. The roughness values for each investigated sample were taken from 3 independent areas.

The surface of polyurethane and their composites were also observed in reflected light with a metallographic microscope Nicon Alphaphot-2YS2 connected with digital photo camera Casio QY2900UX at magnification 1 : 300. The most characteristic places were chosen to the final picture (3-5 micrographs were taken).

Density of polymer samples was determined according to PN-ISO 1183 standard and using an analytical balance equipped with a density determination kit.

Hydrophilicity of cross-linked polyurethanes and their composites with chitosan was estimated by investigation their oil and water sorption. Dried and weighed samples were immersed, respectively, in vegetable oil for 24 hours (at $37^{\circ} \mathrm{C}$ ) and in deionized water for 14 days (at $37^{\circ} \mathrm{C}$ ). Next, the swollen samples were gently blotted with filter paper, weighted and the oil and water sorption were calculated (results were partially presented in [25]). 


\section{Degradability in hydrolytic conditions}

Sensitivity of polyurethanes and their composites on hydrolytic conditions was estimated after their incubation in phosphate buffer solution (PBS, $\mathrm{pH}=7.01$ ) with sodium azide (as a bacteriostatic agent) for 36 weeks at $37^{\circ} \mathrm{C}[26]$.

\section{Degradability in oxidative conditions}

Degradation of polymer samples in oxidative conditions was carried out in $20 \% \mathrm{w} / \mathrm{w}$ hydrogen peroxide in $0.1 \mathrm{~mol} / \mathrm{dm}^{3}$ cobalt chloride solution (high reactive solution) for 16 weeks at $37^{\circ} \mathrm{C}[26,27]$. Because of the extremely reactive oxidative acting of $\mathrm{H}_{2} \mathrm{O}_{2} / \mathrm{CoCl}_{2}[26]$ the incubation time was shorter than for the hydrolysis.

Samples of polyurethanes and their composites were removed, rinsed with distilled water and dried for 4 , 12,24 and 36 weeks in case of phosphate buffer solution and for 4, 8, 12 and 16 weeks in case of oxidative solution. Samples were dried to a constant weight $( \pm 0.0001 \mathrm{~g})$ at $37^{\circ} \mathrm{C}$ in a vacuum drier. The values of experimental weight change were the arithmetic mean of 3-5 measurements. Degradability of polymers was estimated by observation of changes in sample mass, surface structure (by AFM and MM) and thermal properties (by DSC) after incubation of samples in the above mentioned solutions and after drying them to a constant weight.

\section{RESULTS AND DISCUSSION}

The compositions of cross-linked polyurethanes and their composites with chitosan are shown in Table 1. In this study, the hard segment structure was maintained constant (they were built of $\mathrm{H}_{12} \mathrm{MDI}$ and 1,4-BD in the same ratio), while the soft segment composition was varied (the weight ratio of PHB : PCL-triol was $10: 90$ or $30: 70$ ). Polyurethanes were named according to the amount of PHB in soft segment.

The measurements made by DSC method show that polyurethanes and their composites were partially crystalline. The melting endotherms at temperature about $54{ }^{\circ} \mathrm{C}\left(T_{m 1}\right)$, connected with the melting of soft segments, and very small endotherms at temperature about $90{ }^{\circ} \mathrm{C}$ $\left(T_{m 2}\right)$ and $121{ }^{\circ} \mathrm{C}\left(T_{m 3}\right)$, connected with the melting of hard segment domains, were observed in the thermograms (Fig. 1). Small enthalpy $(\Delta H)$ of all endothermic peaks indicated that the crystallinity of cross-linked polyurethanes was low (Table 2). Unexpectedly, with increasing the amount of almost completely amorphous polyhydroxybutyrate (from $10 \mathrm{wt} \%$ for PUR 10 to $30 \mathrm{wt} \%$ for PUR 30) an increase in the crystallinity of soft segments was observed ( $\Delta H_{1}$ increased from 9 to $16 \mathrm{~J} / \mathrm{g}$ ). Probably this was due to an increased distance between network nodes in PCL-triol after using the mixture of polyols, which facilitated the chain ordering in soft segments and, consequently, the formation of crystalline forms.

$\mathrm{T}$ a b 1 e 1. Names and compositions of polyurethanes and their composites with chitosan

\begin{tabular}{l|c|c|c|c}
\hline \multirow{2}{*}{ Symbol of sample } & $\begin{array}{c}\text { Substrates for hard } \\
\text { segments synthesis }\end{array}$ & $\begin{array}{c}\text { Amount of hard } \\
\text { segments } \\
\text { wt } \%\end{array}$ & $\begin{array}{c}\text { Substrates for soft segments } \\
\text { synthesis } \\
\text { wt } \%\end{array}$ & $\begin{array}{c}\text { PUR/Ch composite } \\
\text { wt } \%\end{array}$ \\
\cline { 1 - 4 } PUR 10 & \multirow{2}{*}{$\mathrm{H}_{12}$ MDI + 1,4-BD } & 67.2 & $10 \%$ PHB + 90 \% PCL-triol & $100 / 0$ \\
PUR 10/Ch & & 67.4 & $30 \%$ PHB + 70 \% PCL-triol & $97.5 / 2.5$ \\
\hline PUR 30 & & 64.4 & $100 / 0$ \\
PUR 30/Ch & & 64.2 & $97.5 / 2.5$ \\
\hline
\end{tabular}

T a b l e 2. Thermal properties of polyurethanes and their composites before and after incubation in hydrolytic (HYD) and in oxidative (OX) solutions

\begin{tabular}{|c|c|c|c|c|c|c|c|c|c|c|c|c|}
\hline \multirow[b]{2}{*}{ Symbol of sample } & \multicolumn{2}{|c|}{$T_{m 1^{\prime}}{ }^{\circ} \mathrm{C}$} & \multicolumn{2}{|c|}{$\Delta H_{1}, \mathrm{~J} / \mathrm{g}$} & \multicolumn{2}{|c|}{$T_{m 2}{ }^{\circ} \mathrm{C}$} & \multicolumn{2}{|c|}{$\Delta H_{2^{\prime}} \mathrm{J} / \mathrm{g}$} & \multicolumn{2}{|c|}{$T_{m 3^{\prime}}{ }^{\circ} \mathrm{C}$} & \multicolumn{2}{|c|}{$\Delta H_{3^{\prime}} \mathrm{J} / \mathrm{g}$} \\
\hline & $\begin{array}{c}1^{\text {st }} \\
\text { scan }\end{array}$ & $\begin{array}{c}2^{\text {nd }} \\
\text { scan }\end{array}$ & $\begin{array}{c}1^{\text {st }} \\
\text { scan }\end{array}$ & $\begin{array}{c}2^{\text {nd }} \\
\text { scan }\end{array}$ & $\begin{array}{c}1^{\text {st }} \\
\text { scan }\end{array}$ & $\begin{array}{c}2^{\text {nd }} \\
\text { scan }\end{array}$ & $\begin{array}{c}1^{\text {st }} \\
\text { scan }\end{array}$ & $\begin{array}{c}2^{\text {nd }} \\
\text { scan }\end{array}$ & $\begin{array}{c}1^{\text {st }} \\
\text { scan }\end{array}$ & $\begin{array}{c}2^{\text {nd }} \\
\text { scan } \\
\end{array}$ & $\begin{array}{c}1^{\text {st }} \\
\text { scan }\end{array}$ & $\begin{array}{c}2^{\text {nd }} \\
\text { scan }\end{array}$ \\
\hline PUR 10 & 54.2 & 62.2 & 9.1 & 13.8 & 88.1 & - & 1.8 & - & 121.4 & 120.9 & 0.60 & 0.60 \\
\hline PUR 10 (HYD) & 60.6 & 63.5 & 12.3 & 15.1 & 99.0 & - & 5.3 & - & - & - & - & - \\
\hline PUR 10 (OX) & 56.9 & 69.0 & 14.5 & 11.8 & - & - & - & - & - & - & - & - \\
\hline PUR 10/Ch & 51.9 & 48.9 & 18.6 & 10.7 & 82.7 & - & 2.9 & - & 121.9 & 121.3 & 0.40 & 0.50 \\
\hline PUR 10/Ch (HYD) & 58.1 & 57.3 & 18.7 & 6.8 & - & - & - & - & 119.6 & 120.2 & 0.05 & 0.05 \\
\hline PUR 10/Ch (OX) & 58.5 & 60.1 & 12.6 & 7.2 & - & - & - & - & 125.0 & 120.3 & 0.03 & 0.04 \\
\hline PUR30 & 54.1 & 44.4 & 15.9 & 6.7 & 94.8 & - & 0.7 & - & 120.6 & 119.6 & 0.01 & 0.03 \\
\hline PUR 30 (HYD) & 56.1 & 54.6 & 15.6 & 4.2 & 105.7 & - & 8.0 & - & - & - & - & - \\
\hline PUR 30 (OX) & 57.7 & 77.1 & 11.2 & 5.8 & - & - & - & - & 120.6 & 120.3 & 0.20 & 0.09 \\
\hline PUR 30/Ch & 54.7 & 61.1 & 19.2 & 3.6 & 101.0 & - & 0.05 & - & 125.2 & 130.2 & 0.02 & 0.90 \\
\hline PUR 30/Ch (HYD) & 54.1 & 52.5 & 18.9 & 4.4 & - & - & - & - & 124.4 & 120.5 & 0.10 & 0.03 \\
\hline PUR 30/Ch (OX) & 55.8 & 61.7 & 15.7 & 8.9 & - & - & - & - & 120.6 & 120.4 & 0.12 & 0.05 \\
\hline
\end{tabular}


a)

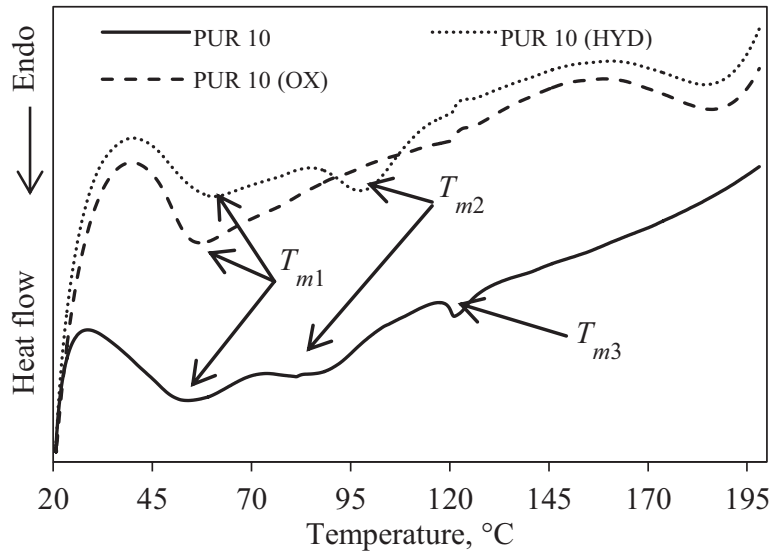

c)

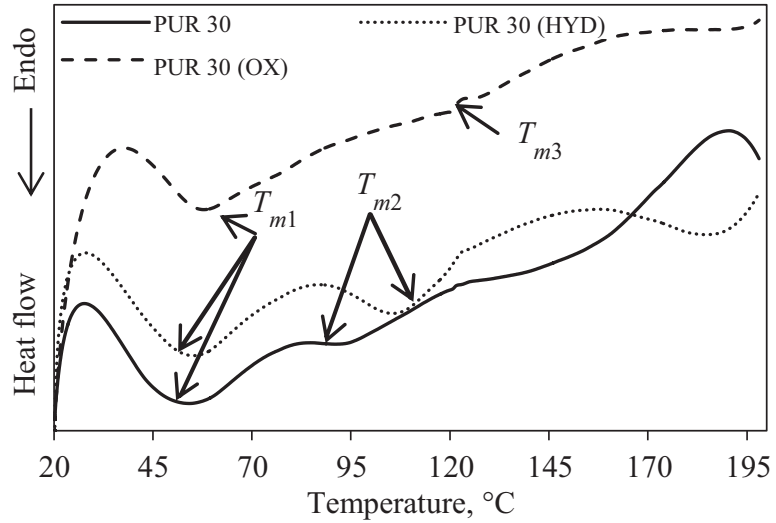

b)

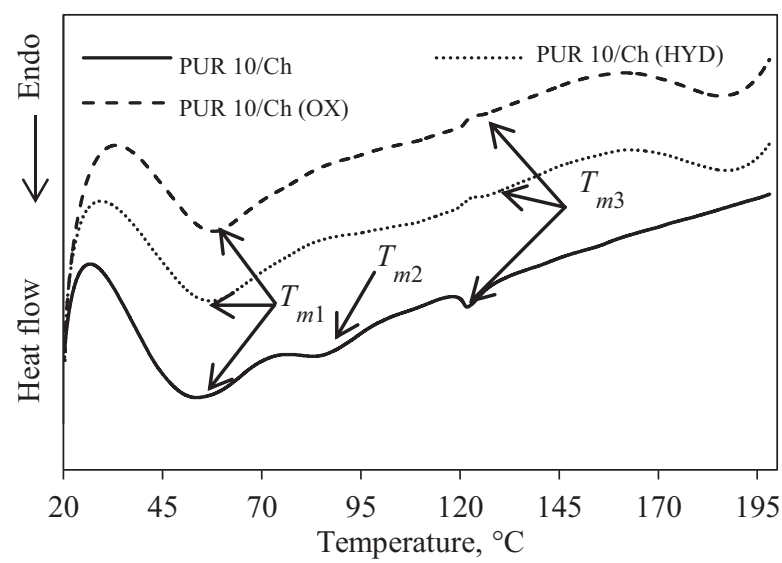

d)

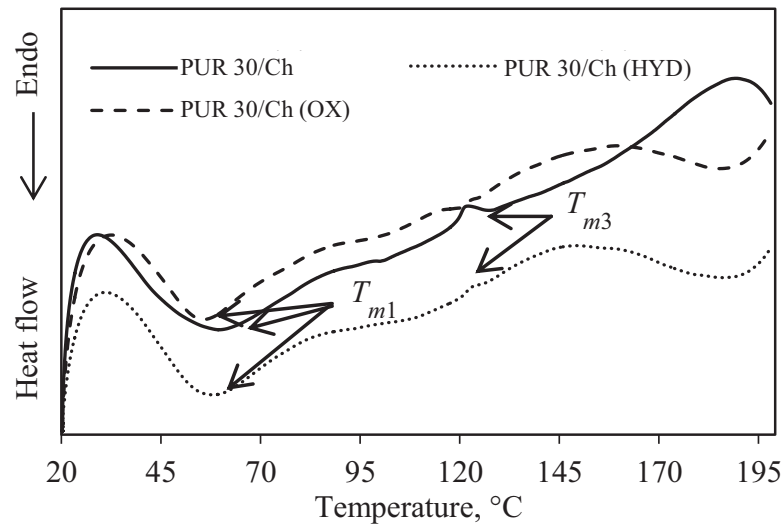

Fig. 1. DSC thermograms (1 ${ }^{\text {st }}$ scan) of: a) PUR 10, b) PUR 10/Ch, c) PUR 30, d) PUR 30/Ch after incubation in hydrolytic (HYD) and oxidative (OX) solutions

Also, the blending of polyurethanes with chitosan affected the melting enthalpy of composites. The amount of chitosan in the composites was small (only $2.5 \mathrm{wt} \%$ ) so generally it could not be observed in DSC thermograms of these composites. However, an endothermic peak at $81.3^{\circ} \mathrm{C}$ (with onset point $48.5^{\circ} \mathrm{C}$ ) with very high enthalpy $(186.5 \mathrm{~J} / \mathrm{g})$, observed in the thermograms of chitosan, was overlapped with peaks in the range $51-55{ }^{\circ} \mathrm{C}$ in the thermograms of composites. This was the reason that the enthalpy of endothermic transition in this region of DSC thermograms was increased.

An exothermic peak observed in DSC thermograms of PUR 30 and PUR 30/Ch (Fig. 1c and Fig. 1d) at a temperature about $180{ }^{\circ} \mathrm{C}$ was probably connected with additional reactions, that occurred in polyurethane structure after thermal degradation of PHB. The amount of PHB in PUR 10 was small, so it was not detected in DSC curves (Fig. 1a and Fig. 1b).

Density and hydrophilicity of polymer are important factors which determine the material degradability.

The densities of polyurethanes and their composites were similar (about $1.07 \mathrm{~g} / \mathrm{cm}^{3}$, Table 3).

Cross-linked polyurethanes and their composites absorbed very small amount of vegetable oil after 24 hours of incubation - their weight changed insignificantly (Table 3) in sorption tests. It suggested a hydrophilic character of the materials and their potential resistance to lip-
$\mathrm{T}$ a b l e 3. Density of PUR and PUR/Ch and their swelling in vegetable oil

\begin{tabular}{l|c|c}
\hline Symbol of sample & $\begin{array}{c}\text { Density } \\
\mathrm{g} / \mathrm{cm}^{3}\end{array}$ & $\begin{array}{c}\text { Oil sorption } \\
\text { wt \% }\end{array}$ \\
\hline PUR 10 & $1.07 \pm 0.03$ & $0.5 \pm 0.1$ \\
PUR 10/Ch & $1.08 \pm 0.05$ & $1.0 \pm 0.1$ \\
PUR 30 & $1.06 \pm 0.03$ & $0.7 \pm 0.1$ \\
PUR 30/Ch & $1.08 \pm 0.02$ & $0.6 \pm 0.2$ \\
\hline
\end{tabular}

ids. Polycaprolactone is generally a hydrophobic polymer and its hydrophobicity increases with the chain growth (molecular mass increase). But in the case of polycaprolactone triol (with $M_{n}=900$ ) the hydrophobic effect of hydrocarbon chains is reduced. Using it as a part of soft segments did not influence the hydrophobicity of polyurethanes.

The susceptibility of polymers to environment determines their application. Degradation of polymer consists of three stages in aqueous environment: water sorption (incubation stage), degradation of sensitive bonds and moieties (induction stage), and dissolution of water-soluble entities (erosion stage) [11]. Thus, the capacity of water absorption is an important feature of degradable polymer.

Despite the long time of incubation of the samples in deionized water (2 weeks) they did not reach a saturation state (Fig. 2). Only the weight of PUR 10 samples 


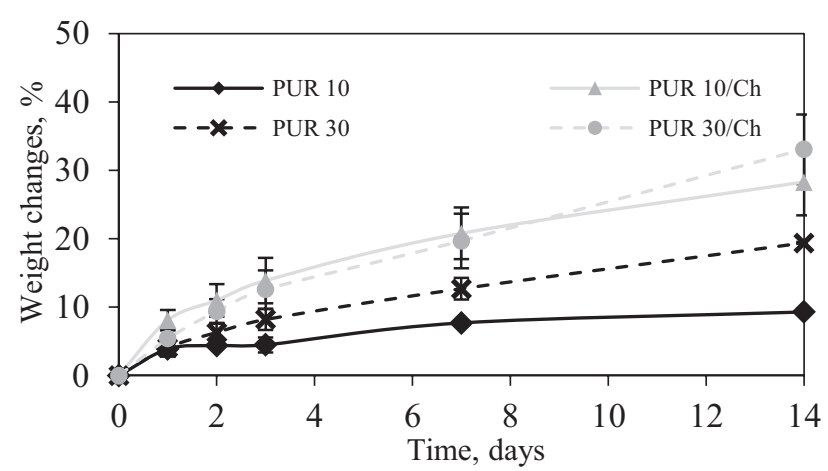

Fig. 2. Weight changes of polyurethanes and their composites after incubation in deionized water

was almost stable during last week of incubation (no more water molecules could migrate into this cross-linked polyurethane). PUR 30, with higher amount PHB in soft segments, and simultaneously with lower cross-linking, absorbed more water than PUR 10. As it was said before, the presence of PHB in soft segments increases their crystallinity (Table 2), what could make water sorption difficult, but on the other hand it causes an increase in the free space between polyurethane chains. Soft segments in both polyurethanes were built with blended polyols: PHB-diol and PCL-triol. In case when amount of PHB-diol was small (only $10 \mathrm{wt} \%$ soft segments, as in PUR 10) polyurethane was highly cross-linked, the chains were stiff and not mobile, and molecules of water could not migrate into PUR network. In case when amount of PHB-diol was increased (and simultaneously the amount of PCL-triol was reduced) the polymer with a smaller number of cross-linking nodes was obtained (PUR 30). Therefore, the soft segments of PUR 30 were built of long, linear chains, which (because of secondary $\mathrm{OH}$ in $\mathrm{PHB}$ ) contained methyl side groups. In this case, chains were not allowed to get close to each other and the migration of water molecules was facilitated.

As it was expected, blending of polyurethanes with chitosan increased the amount of water absorbed by the samples (Fig. 2).

The standard deviation $(S D)$ was higher for the measurements of the swelling of composite than in case of polyurethane samples. The maximum $S D$ of water sorption by polyurethanes was $1.5 \%$ whereas $S D$ for composites exceeded $5 \%$. This higher value of standard deviation indicated that the presence of chitosan in composites made their structure less uniform than that of polyurethanes and the individual samples absorbed the water in varying degrees.

As it was said before, the oxidative solution used for the estimation of polyurethane degradability was very reactive (Fig. 3). According to the results of the study conducted by Christenson [26] the treatment of samples with $20 \%$ hydrogen peroxide $/ 0.1 \mathrm{~mol} / \mathrm{dm}^{3}$ cobalt chloride solution at $37^{\circ} \mathrm{C}$ reproduced the chemical and physical characteristics of in vivo degradation at an accelerated rate (Christenson stated that "an oxidative $\mathrm{H}_{2} \mathrm{O}_{2} / \mathrm{CoCl}_{2}$ treatment accurately reproduced the one year in vivo effect in
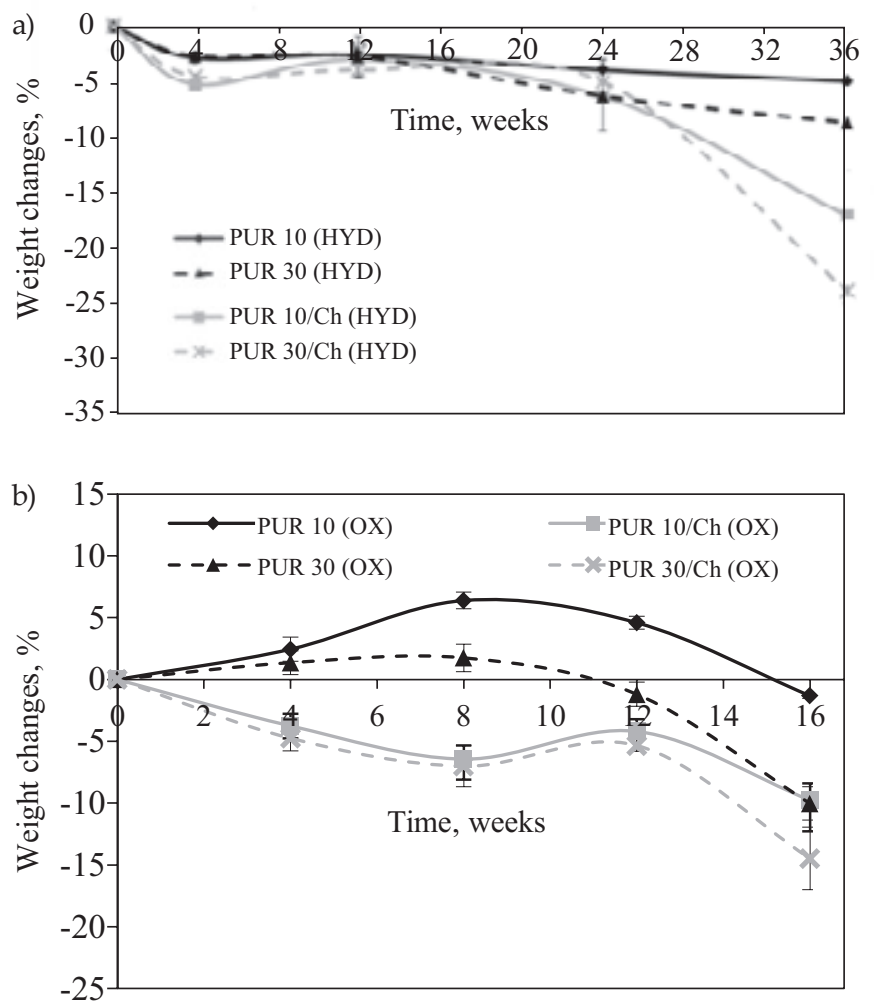

Fig. 3. Sample weight changes of polyurethanes and their composites after incubation: a) in hydrolytic solution, b) in oxidative solution

only 24 days") [26]. In our study, the time of incubation of polyurethane samples in oxidative solution was shorter (16 weeks) than in phosphate buffer solution (36 weeks). Despite the high reactivity of oxidative solution the reductions in sample weights at the end of the experiment were small. So it could be stated that polyurethanes and their composites with chitosan degraded faster in hydrolytic than in oxidative solution (Fig. 3). It indicates that the degradation process takes place mainly by hydrolysis of ester groups. Degradation kinetics was faster for the samples with higher amount PHB in soft segments (PUR 30 and PUR 30/Ch), what was the result of more linear structure, lower cross-linking degree, and higher amount of ester moieties in PUR 30 than in PUR 10.

At first stage of the incubation in oxidative solution the weight of polyurethane samples increased. It is thought that under the influence of oxidizing agents the structure of PUR 10 and PUR 30 is reorganized. The short chains (that form in consequence of degradation) were not eluted from the polymer network, but they introduce additional cross-links. The oxidative solution was not transparent and left the dark sediment on the surface of the samples and containers used for incubation. It is supposed that the sediments from oxidizing solution were trapped inside the polyurethane network, increasing the weight of the samples. At the next stage, the short chains, generated as a result of the degradation, were eluted from the polymer network and the weight of the samples decreased. 
Blending of polyurethanes with chitosan accelerated the degradation process (Fig. 3a and Fig. 3b). It is known that chitosan is trapped in the polyurethane network by hydrogen bonds between $-\mathrm{OH}$ and $-\mathrm{NH}_{2}$ groups of chitosan and $-\mathrm{C}=\mathrm{O}$ and $-\mathrm{NH}-$ groups in PUR chains [22]. Chitosan used for preparation of composites was triturated in mortar and had a particle size of 50-350 $\mu \mathrm{m}$. Thus, the number of hydrogen bonds that kept the particles of chitosan in the polyurethane network was lower than, e.g., in case of superfine chitosan powder (with particle size $0.2-12 \mu \mathrm{m}$ ) [22]. Therefore, the chitosan particles were eluted from the composite during the incubation in solutions, what additionally facilitated the movement of water molecules into polyurethane network.

As in the case of water sorption larger standard deviation values were found for composites $(0.2-7.9 \%)$ than for polyurethanes $(0.2-3.9 \%)$ after the incubation in phos- phate buffer (Fig. 3a). The tendency after incubation in oxidative solution was similar (Fig. 3b).

The melting temperature $\left(T_{m 1}\right)$ of soft segments increased after incubation in degradative solutions what suggested an increase in the crystallinity of soft segments (short chains, created after chain scission during degradation, were mobile, what facilitated the formation of crystalline phase). It also could be due to the degradation of the amorphous phase in the first stage. In this case the melting enthalpy $\left(\Delta H_{1}\right)$ of soft segments increased, such as after the incubation of PUR 10 in both solutions (Table 2). On the other hand, increasing of melting temperature of soft segments could also suggest their additional cross-linking. In these cases, the melting enthalpy decreased after incubation in the solutions, which was observed for PUR 30 and both composites (Table 2).

$\mathrm{T}$ a b l e 4. Surface of polyurethanes and their composites under metallographic microscope before and after incubation in hydrolytic ( 36 weeks) and oxidative ( 16 weeks) solutions

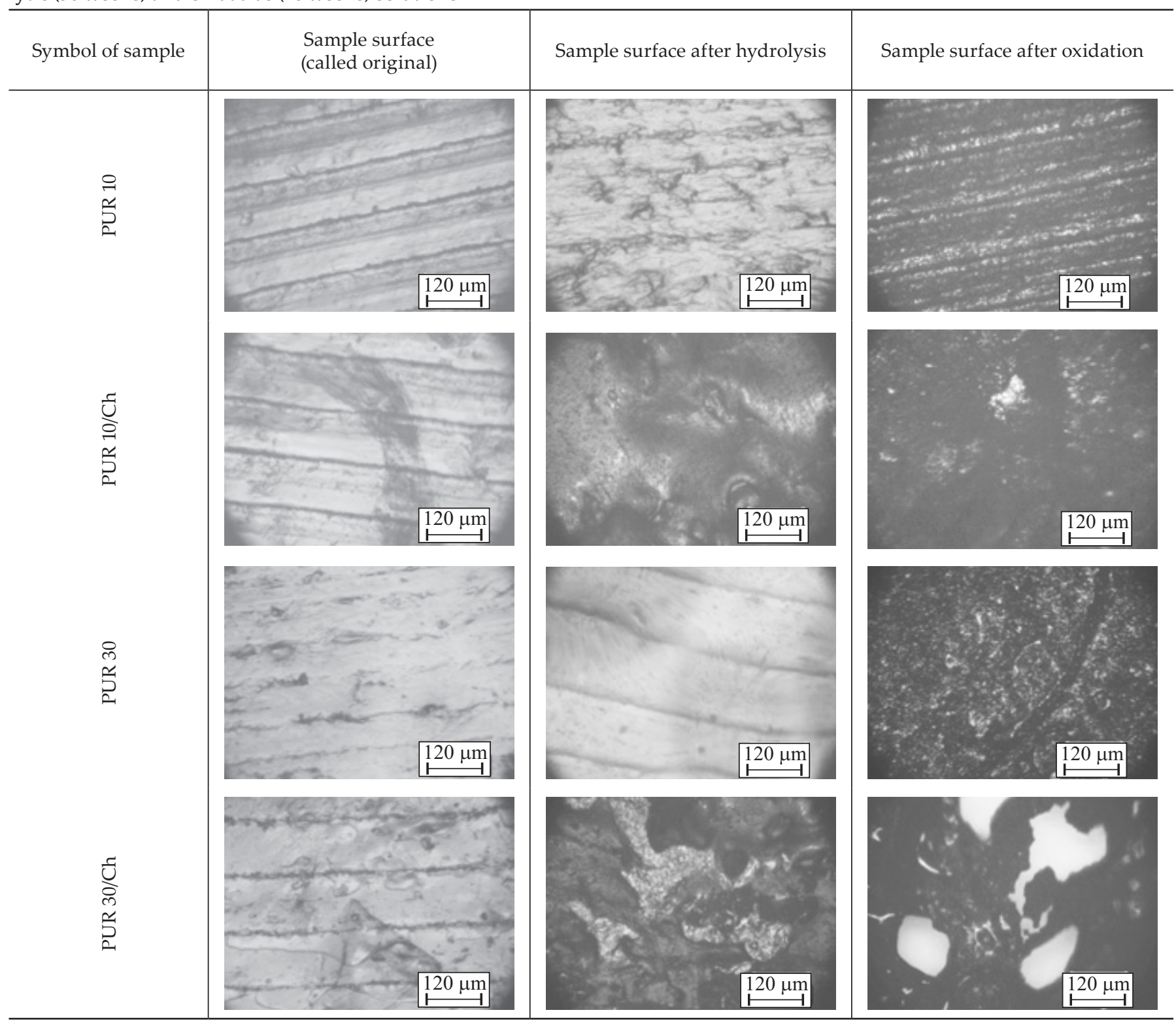


$\mathrm{T}$ a b 1 e 5. Surface of polyurethanes and their composites at AFM phase image ( $5 \mu \mathrm{m} \times 5 \mu \mathrm{m})$ before and after incubation in hydrolytic ( 36 weeks) and oxidative ( 16 weeks) solutions

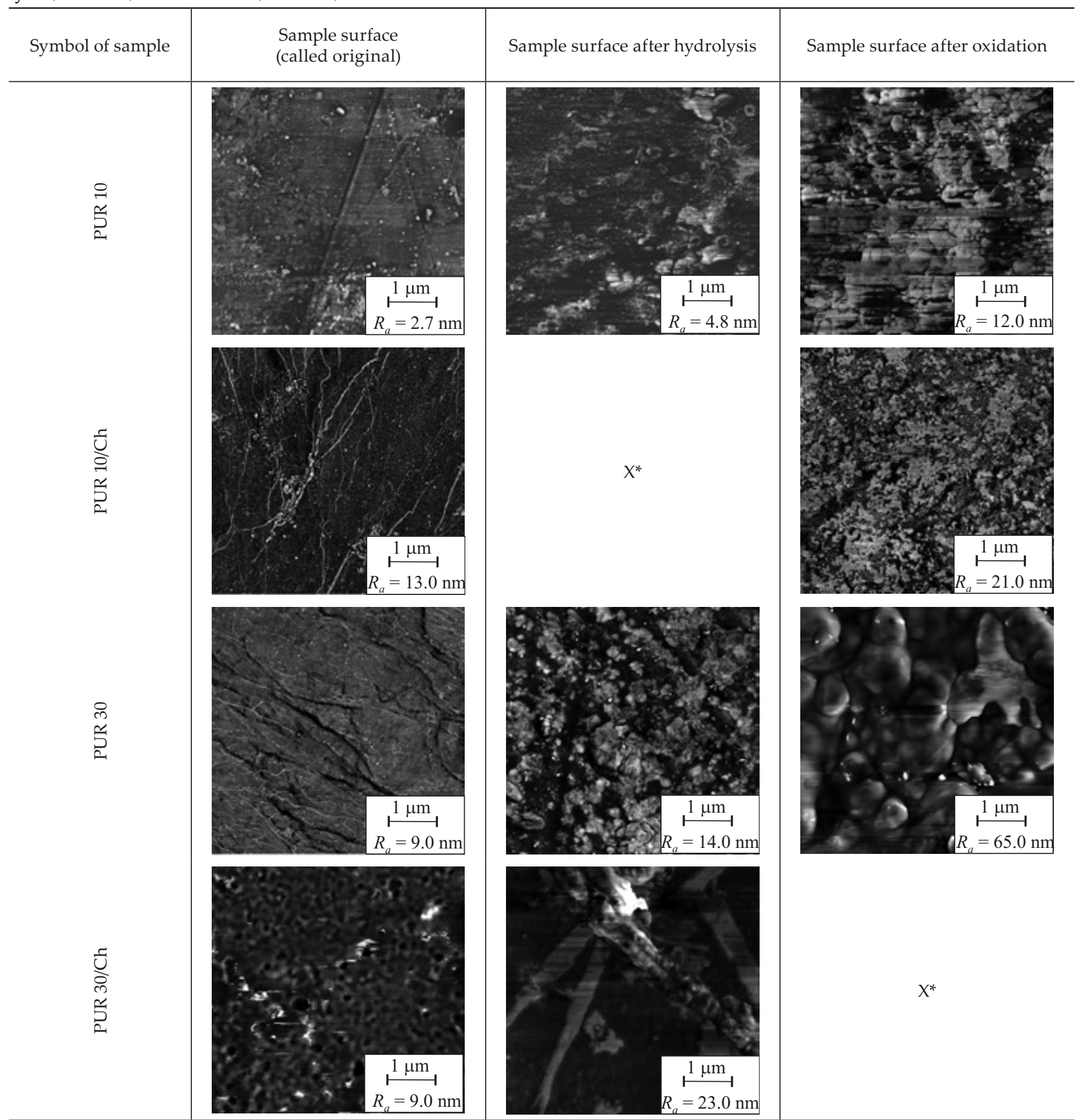

$\mathrm{X}^{*}$ - because of high roughness of polymer samples the AFM investigation could not be performed.

Also, the changes in temperature and melting enthalpy of endotherms observed in the thermograms at higher temperatures suggested the structural changes of polyurethanes and their composites after incubation in both solutions (Table 2). It was especially visible for PUR 10 and PUR 30 where $T_{m 2}$ (with $\Delta H_{2}$ ) increased, respectively, from $88.1{ }^{\circ} \mathrm{C}$ $(1.8 \mathrm{~J} / \mathrm{g})$ and $94.8^{\circ} \mathrm{C}(0.7 \mathrm{~J} / \mathrm{g})$ to $99.0^{\circ} \mathrm{C}(5.3 \mathrm{~J} / \mathrm{g})$ and $105.7^{\circ} \mathrm{C}$ $(8.0 \mathrm{~J} / \mathrm{g})$ after incubation in hydrolytic conditions (Table 2).

Changes in the structure of polyurethanes and their composites, which appeared as a result of their degrada- tion, caused the formation of crystallites with $T_{m}$ about $180^{\circ} \mathrm{C}$. The endothermic peaks, observed in DSC thermograms of the first heating scan, disappeared after the second heating (Table 2).

Representative MM and AFM images of polymer samples before and after incubation in degradative solutions are shown, respectively, in Table 4 and Table 5.

Cross-linked polyurethanes were transparent and, in consequence, the oriented and parallel strips of surface of Teflon plates (used for PUR formation) were observed 
under metallographic microscope with reflected light (Table 4, original samples). The apparent surface of PUR samples between strips was rather smooth and uniform. In composites, the chitosan particles, trapped inside the polyurethane matrices, were seen under microscope. Changes in surface roughness after the introduction of chitosan into polyurethanes were not observed.

The comparison of the surface structure of polyurethanes and composites before and after incubation in degradative solutions confirmed their degradation. The surface of all samples was eroded. The surface of PUR 30 incubated in buffer solution seemed to be smoother and more "eluted" than original sample, whereas after degradation in oxidative solution the cracks appeared on the surface. The lowest changes were observed for PUR 10 (with low amount of PHB) incubated in oxidative solution, what was in agreement with the lowest changes in sample weight (Fig. 3b). The visible depression was created on the surface of composites as a result of chitosan particles rinsing from polyurethanes matrices, both after hydrolysis and oxidization processes. Generally, higher surface changes of degraded composites than that of neat polyurethanes were in agreement with their higher weight loss (Fig. 3).

AFM analysis confirmed that degradation process affected strongly the roughness of the investigated samples leading to less uniform and rugged surface. PUR film surfaces which previously were quite smooth, became much rougher after incubation in hydrolytic and oxidative solutions. The changes were much more visible for PUR 30 and its composite where average roughness varied from $9 \mathrm{~nm}$ for original PUR 30 to 14 and $65 \mathrm{~nm}$ for hydrolyzed and oxidized PUR 30, respectively (Table 6). The degraded surface of PUR 10 and PUR 10/Ch appeared like an irregular distribution of small humps (white zones) on continuous hollows (black zones). This is confirmed by two times increase in the roughness for hydrolyzed surface and four times for the oxidized one. The higher number of big humps and crevices was observed on the surface

T a b l e 6. Average roughness $\left(R_{a}\right)$ of polyurethanes and their composites before and after incubation in hydrolytic ( 36 weeks) (HYD) and oxidative (16 weeks) (OX) solutions

\begin{tabular}{l|c}
\hline \multicolumn{1}{c|}{ Symbol of sample } & $R_{a^{\prime}} \mathrm{nm}$ \\
\hline PUR 10 & 2.7 \\
PUR 10 (HYD) & 4.8 \\
PUR 10 (OX) & 12.0 \\
PUR 10/Ch & 13.0 \\
PUR 10/Ch (OX) & 21.0 \\
PUR 30 & 9.0 \\
PUR 30 (HYD) & 14.0 \\
PUR 30 (OX) & 65.0 \\
PUR 30/Ch & 9.0 \\
PUR 30/Ch (HYD) & 23.0 \\
\hline
\end{tabular}

of PUR 30 in comparison to PUR 10, what was in a good agreement with its higher weight loss (Fig. 3).

\section{CONCLUSIONS}

Cross-linked polyurethanes, based on degradable polyols \{polycaprolactone triol and poly $([R, S]-3$-hydroxybutyrate)\}, and their composites with chitosan were degraded in hydrolytic and oxidative solutions. Changes in sample weights, thermal properties and surface structure of incubated polymers indicated that, despite of cross-linked network of polyurethanes, they were degradable (probably via hydrolysis of ester bonds). By adding higher amount of poly([R,S]-3-hydroxybutyrate) into soft segments and blending of polyurethanes with chitosan the degradation process was accelerated. An increase in melting temperature and melting enthalpy of soft segments suggested their additional cross-linking after incubation in degradative solutions. The surface of all samples was eroded, especially with visible depression created due to rinsing of chitosan particles from composites. PUR with high content of PHB in soft segments (PUR 30 and PUR 30/Ch) eroded much more intensive (with cracked and more non-uniform structure) than PUR 10 and PUR 10/Ch. PUR with PHB and chitosan is prospective as biodegradable material and the further investigation with estimation of degradation products will be performed.

\section{REFERENCES}

[1] Singhal P., Small W., Cosgriff-Hernandez E. et al.: Acta Biomaterialia 2014, 10, 67. http://dx.doi.org/10.1016/j.actbio.2013.09.027

[2] Pyun D.G., Choi H.J., Yoon H.S. et al.: Colloid Surface B: Biointerfaces 2015, 135, 699. http://dx.doi.org/10.1016/j.colsurfb.2015.08.029

[3] Guelcher S.A., Srinivasan A., Dumas J.E. et al.: Biomaterials 2008, 29, 1762.

http://dx.doi.org/10.1016/j.biomaterials.2007.12.046

[4] Oprea S.: Composites: Part B: Engineering 2013, 44, 76. http://dx.doi.org/10.1016/j.compositesb.2012.07.018

[5] Lee T.J., Kwon S.H., Kim B.K.: Progress in Organic Coatings 2014, 77, 1111.

http://dx.doi.org/10.1016/j.porgcoat.2014.03.011

[6] Janik H., Sienkiewicz M., Kucinska-Lipka J.: “Handbook of Thermoset Plastics" (Ed. Goodman S.H., Dodiuk-Kenig H.), Elsevier, 2014, Chapter 9, pp. 253-295.

[7] Barrioni B.R., de Carvalho S.M., Oréfice R.L.: Materials Science and Engineering: C 2015, 52, 22. http://dx.doi.org/10.1016/j.msec.2015.03.027

[8] Mourya V.K., Inamdar N.N.: Reactive and Functional Polymers 2008, 68, 1013.

http://dx.doi.org/10.1016/j.reactfunctpolym.2008.03.002

[9] Muzzarelli R.A.A.: Carbohydrate Polymers 2009, 76, 167.

http://dx.doi.org/10.1016/j.carbpol.2008.11.002 
[10] Usman A., Zia K.M., Zuber M. et al.: International Journal of Biological Macromolecules 2016, 86, 630. http://dx.doi.org/10.1016/j.ijbiomac.2016.02.004

[11] Muzaffar S., Bhatti I.A., Zuber M. et al.: International Journal of Biological Macromolecules 2016, 93, 145. http://dx.doi.org/10.1016/j.ijbiomac.2016.08.068

[12] Owczarczak A., Schroeder G.: "Chemiczna funkcjonalizacja powierzchni dla potrzeb nanotechnologii" (Ed. Schroeder G.), Cursiva, 2011, p. 131. ISBN 978-83-62108-07-7

[13] Salehi E., Daraei P., Shamsabadi A.A.: Carbohydrate Polymers 2016, 152, 419. http://dx.doi.org/10.1016/j.carbpol.2016.07.033

[14] Wolska J.: Progress on Chemistry and Application of Chitin and its Derivatives 2016, XXI, 203. http://dx.doi.org/10.15259/PCACD.21.22

[15] Hamed I., Özogul F., Regenstein J.M.: Trends in Food Science \& Technology 2016, 48, 40. http://dx.doi.org/10.1016/j.tifs.2015.11.007

[16] Modrzejewska Z.: Inżynieria i Aparatura Chemiczna 2011, 50 (5), 74.

[17] Zia K.M., Anjum S., Zuber M. et al.: International Journal of Biological Macromolecules 2014, 66, 26. http://dx.doi.org/10.1016/j.ijbiomac.2014.01.073

[18] Silva S.S., Menezes S.M.C., Garcia R.B.: European Polymer Journal 2003, 39, 1515. http://dx.doi.org/10.1016/S0014-3057(03)00013-2

[19] Xu D., Wu K., Zhang Q. et al.: Polymer 2010, 51, 1926. http://dx.doi.org/10.1016/j.polymer.2010.03.008
[20] Kara F., Aksoy E.A., Yuksekdag Z.: Carbohydrate Polymers 2014, 112, 39.

http://dx.doi.org/10.1016/j.carbpol.2014.05.019

[21] Brzeska J., Heimowska A., Morawska M. et al.: Polimery 2015, 60, 391.

http://dx.doi.org/10.14314/polimery.2015.391

[22] Zuo D.Y., Tao Y.Z., Chen Y.B., Xu W.L.: Polymer Bulletin 2009, 62, 713. http://dx.doi.org/10.1007/s00289-009-0049-8

[23] Arslan H., Adamus G., Hazer B., Kowalczuk M.: Rapid Communication in Mass Spectrometry 1999, 13, 2433. ht t p://dx.doi.org/10.1002/(S I C I) 1097 0231(19991230)13:24<2433::AID-RCM808>3.0.CO;2-X

[24] Wojtasz-Pająk A., Szumilewicz J.: Progress on Chemistry and Application of Chitin and its Derivatives 2009, XIV, 15.

ID 39ad33b2-9f0c-487e-a388-1df2d91b649f

[25] Brzeska J., Albecka K., Sikorska W. et al.: "Composites of crosslinked polyurethanes with chitosan", Proceedings of the Conference Biopolymer Materials and Engineering, Slovenj Gradec, Slovenia 15-17 July 2015, p. 67. http://www.bimate.si/Proceedings

[26] Christenson E.M., Patel S., Anderson J.M., Hiltner A.: Biomaterials 2006, 27, 3920.

[27] Feng Y., Li Ch.: Polymer Degradation and Stability 2006, 91, 1711. http://dx.doi.org/10.1016/j.polymdegradstab.2005.12.002

Received 8 XI 2016. 